\title{
An Evaluation of the Beyond High School Model on the Self- Determination of Students With Intellectual Disability
}

Career Development and Transition for Exceptional Individuals 35(2) 76-84

(C) 2012 Hammill Institute on Disabilities Reprints and permission: sagepub.com/journalsPermissions.nav DOI: | 0.1 | 777/08857288| |432|65 http://cdtei@sagepub.com

(SAGE

\author{
Susan B. Palmer', Michael L. Wehmeyer', Karrie A. Shogren², \\ Kendra L. Williams-Diehm ${ }^{3}$, and Jane H. Soukup'
}

\begin{abstract}
Students with intellectual disability are often served in community-based services to promote effective adult outcomes in employment, community inclusion, and independent living (Gaumer, Morningstar \& Clark (2004). Beyond High School (Wehmeyer, Garner, Lawrence, Yeager, \& Davis, 2006), a multi-stage model to promote student involvement in educational planning, was effectively used by 109 students with mild and moderate levels of intellectual disability between 17.8 and $2 \mathrm{l}$ years of age to increase student abilities. Results are discussed in regard to improved transition opportunities for individuals with intellectual disability such as those afforded through post-secondary education.
\end{abstract}

\section{Keywords}

intellectual disability, postschool outcomes, self-determination

The Individuals With Disabilities Education Act (IDEA) mandates that states provide a free, appropriate public education to children with disabilities residing within that state and between the ages of 3 and 21, except when its application to those children would be inconsistent with State law or practice. In most states, students between the ages of 18 and 21 with intellectual or developmental disabilities remain eligible for services from the public school system, after their same-age peers have graduated. The intent of 18-21 services is to provide an opportunity for intensive, community-based learning experiences that lead directly to adult outcomes such as employment, community inclusion, and independent living (Gaumer, Morningstar, \& Clark, 2004; Grigal, Dwyre, \& Davis, 2006).

One predictor of postsecondary success in employment and other outcomes mentioned above is self-determination (Field, Sarver, \& Shaw, 2003). The construct self-determination "refers to the volitional acts that enable one to act as the primary causal agent in one's life and to maintain or improve one's quality of life" (Wehmeyer, 2006, p. 117). During the school years, it has become common practice to support students with disabilities to exercise choice making, decision making, problem solving, goal setting, and a number of other skills that support eventual self-determined characteristics and more effective transitions (Eisenman,
2001; Thoma \& Getzel, 2005; Wehmeyer \& Schwartz, 1997) Wehmeyer (2003) suggested that the characteristics of acting autonomously, being self-regulated, initiating and responding to events in a psychologically empowered manner, and acting in a self-realizing manner to recognize the effects of one's actions on others and the environment indicate volitional self-determined behavior. Wehmeyer and Palmer (2003) found that postschool outcomes were linked to self-determination. Self-determination and student involvement are identified as evidence-based practices in secondary transition (Test et al., 2009).

Instructional programming for students with intellectual disabilities supporting self-determination has been undergoing a number of changes within the current standardsbased education legislated by the No Child Left Behind Act (NCLB, 2001) and the current Race to the Top (RTTT,

\footnotetext{
'University of Kansas, Lawrence, USA

${ }^{2}$ University of Illinois, Champaign, USA

${ }^{3}$ University of Oklahoma, Norman, USA
}

Corresponding Author:

Susan B. Palmer, University of Kansas, 1200 Sunnyside Ave., 3136

Haworth Hall, Lawrence, KS, 66045

Email: spalmer@ku.edu 
2010). Stodden, Galloway, and Stodden (2003) discussed the complexities of the ongoing changes in secondary school curricula and the impact on postsecondary students with disabilities. To further enhance the effective education of students with intellectual disabilities during school, additional postschool data are collected, to gather information on effective outcomes. Data for Indicator 14 of Part B of IDEA's transition beyond high school must be reported annually to the federal government by states, including the number of former students enrolled in higher education and in competitive employment, or the students in both higher education/training and employment within 1 year of leaving high school (Individuals With Disabilities Education Act, 2004). Thus, it is important for schools to provide highquality services for students with disabilities who are enrolled to encourage positive postschool outcomes. Services for students between the ages of 18 and 21 years vary but should still promote positive outcomes. Based on a survey of the extant literature, Wehmeyer, Garner, Lawrence, Yeager, and Davis (2006) identified a number of "quality indicators" of high-quality 18-21 services:

1. High quality educational services for students with intellectual and developmental disabilities ages 18-21 are provided in age-appropriate environments allowing for social interaction and promoting community inclusion.

2. High quality educational services are ecologically valid and community-based.

3. High quality services are outcome-oriented.

4. Academic instruction in quality programs is functional and focused on outcomes.

5. Quality services emphasize person centered planning and active family involvement.

6. Quality services involve active participation of adult service providers in planning and implementation.

7. Quality services implement best practice in transition.

8. Quality services foster active student involvement and promote self-determination. (pp. 3-5)

There is a need for models that can be implemented to ensure that such instructional experiences for students receiving 18-21 services are present and of high quality. A number of such models have been introduced, including the DO-IT CAREERS model (Burgstahler, 2001) and programbased and independent support models (Grigal et al., 2006). Wehmeyer and colleagues (2006) proposed a multistage model, titled the Beyond High School (BHS) model, designed to infuse efforts to promote self-determination into quality 18-21 supports and to promote active student engagement. A field test of 15 students with intellectual disabilities between the ages of 18 and 21 years setting
37 goals of varying topics through the BHS model. Goal Attainment Scaling scores indicated that set goals were met at or above the expected levels, and the model was initially effective, but more study was needed to determine if the BHS model affects self-determination levels (Wehmeyer et al., 2006).

The BHS model (described in more detail subsequently) consists of three distinct stages including use of Whose Future Is It Anyway? (WFA; Wehmeyer et al., 2004) and the Self-Determined Learning Model of Instruction (SDLMI; Wehmeyer, Palmer, Agran, Mithaug, \& Martin, 2000), a self-regulated problem-solving model of instruction used in conjunction with a facilitator and the student. Throughout the BHS model, the student is engaged in becoming more involved in planning and decision making, learning skills to be able to more independently solve problems and set and achieve goals to be more self-determined related to postsecondary outcomes, in this instance. The purpose of the present study was to determine if the BHS model does, as proposed, promote student self-determination as an outcome of its implementation.

\section{Method}

\section{Participants}

Study participants were 109 high school students in three states (Kansas, Missouri, and Texas) and 23 school districts who were receiving special education services under the categorical area of intellectual disabilities and were identified by districts as being served in the district's 18-21 program. Special education teachers were asked to provide an indicator of ability for students estimating student performance level and support needs for each student. The teachers were case managers for each student and involved in student Individualized Education Program (IEP) support. Thus, teachers were able to use student records and firsthand knowledge gleaned over time to provide a rating of level of cognitive ability. Although all students were identified as receiving services under the Intellectual Disability (ID) category, current IQ scores were available for only a subset of the sample, and, to have some indication of student level of intellectual impairment, we asked teachers to identify the student as having either mild (54\%) or moderate $(46 \%)$ intellectual impairments. At the start of the study, participants ranged in age from 17.2 to 21.8 years $(M=$ $18.8 ; S D=.88$ ). Females comprised $37 \%$ and males $62 \%$ of the sample. The majority of participants were Caucasian (60\%), although other race/ethnicities were also represented: Hispanic (12\%), African American (21\%), Native American/Alaskan Native (4\%), and Other (3\%). Teachers reported that $47 \%$ of students were eligible for free and/or reduced lunch. 


\section{Design and Procedures}

Participants were recruited to participate in a study examining the impact of the BHS model's implementation on student self-determination over 2 years' time. Project personnel contacted school districts and provided them with information about the study. Districts that agreed to participate $(n=23)$ identified teachers to participate, who in turn identified students. Signed, informed consent from each participant's parent or guardian was obtained, as was consent from the student. After consent was obtained, baseline data were collected. Baseline data consisted of demographic information about the student and his or her educational experiences and multiple measures of self-determination, described subsequently. Training was then provided to teachers on the BHS model's implementation, after which teachers implemented the model for the remainder of the year, typically for a duration of 24 weeks. The following year, teachers involved received a brief retraining at the beginning of the year, and again, continued implementing the model for another 24 weeks prior to posttesting. Students were assessed at the end of the 2 nd year with the same measures as were implemented at baseline to explore changes in student self-determination. Study personnel prompted teachers monthly related to providing instruction and provided feedback via email about the instructional process, but teachers were not directly observed due to the large number of programs and the excessive time and travel needed to provide direct oversight.

As is expected in research across multiple years, there was attrition in the sample. Only 79 of the students who completed baseline assessments were available to complete the postintervention assessments, a $28 \%$ attrition rate. Students did not complete postintervention assessments for a variety of reasons (e.g., moving, dropping out of school, changing classes). Analyses were conducted to examine for differences between the 79 completers and the 30 noncompleters on baseline measures of self-determination, and no significant differences were found.

Intervention. The BHS model (Wehmeyer et al., 2006; Figure 1) is a multistage model designed to promote student involvement in educational planning and to promote selfdetermination. In stage 1 of the BHS model, students begin to establish short- and long-term goals based on personal preferences, identified abilities, and interests, while becoming more involved with the IEP process. First, students are involved in targeted instruction teaching them to self-direct planning and decision making specific to the transition process. This could be accomplished through multiple informal or formal strategies or methods that prepare students to participate in or direct their educational planning process. In the context of our evaluation of the BHS model's impact on self-determination, students were involved in the WFA process (Wehmeyer et al., 2004). The WFA is a self-regulated transition planning process that has been shown to result in enhanced self-determination and greater transition planning knowledge and beliefs (Wehmeyer \& Lawrence, 1995; Wehmeyer, Palmer, Lee, Williams-Diehm, \& Shogren, 2011).

Next, students were taught to self-direct the transition goal setting, action planning, and program implementation process using the SDLMI (Wehmeyer et al., 2000). Although there is insufficient space for a comprehensive description of this instructional model in this article, the SDLMI is a model of teaching based on the principals of self-determination, self-regulation, and student-directed learning that enables teachers to teach students to self-direct the instructional process from goal setting through action planning to selfmonitoring and self-evaluation. Students learn a series of three sets of four self-instruction questions, each set of which forms a problem-solving sequence that enables students to solve the following problems: "What is my learning goal?" "What is my plan?" and "What have I learned?" As such, students are actively in control of the learning process from goal setting through evaluation. Research has shown that instruction using the SDLMI is causally linked to improved academic and transition goal attainment and access to the general education curriculum (Shogren, Palmer, Wehmeyer, Williams-Diehm, \& Little, in press) and enhanced selfdetermination (Wehmeyer, Shogren, et al., in press).

Stage 2 implementation of the BHS model involves convening a student-directed, person-centered planning meeting that brings together stakeholders in the instructional process to work with students to refine goals, as needed; to support the student as he or she implements the second phase of the SDLMI (What is my plan?); and to enable the student to provide informed consent with regard to implementation of the instructional program. This meeting is not intended to be the mandated IEP meeting, although these activities certainly can occur at an IEP meeting. Instead, the meeting should bear a closer resemblance to a personcentered planning process where stakeholders come together on a more frequent basis to identify hopes and dreams, to identify natural supports, and so forth. The meeting varies from traditional person-centered planning meetings, however, in scope, intent, and process. First, it is intended that this is the student's meeting. The teacher or person-centered planning facilitator should support the student, and, using skills he or she acquired in the first stage of the model, the student is to present goals he or she has generated. The second difference is that these student goals provide the foundation for the meeting's purpose and direction. Other stakeholders are encouraged to help the student refine the goals, more clearly define the goals, or identify objectives to reach goals, but not to criticize or replace goals. These goals will, likely, form only a subset of the total goals on a student's IEP, but the intent is that students have a forum to discuss their goals and gather support of parents, family members, teachers, and others to make those goals 


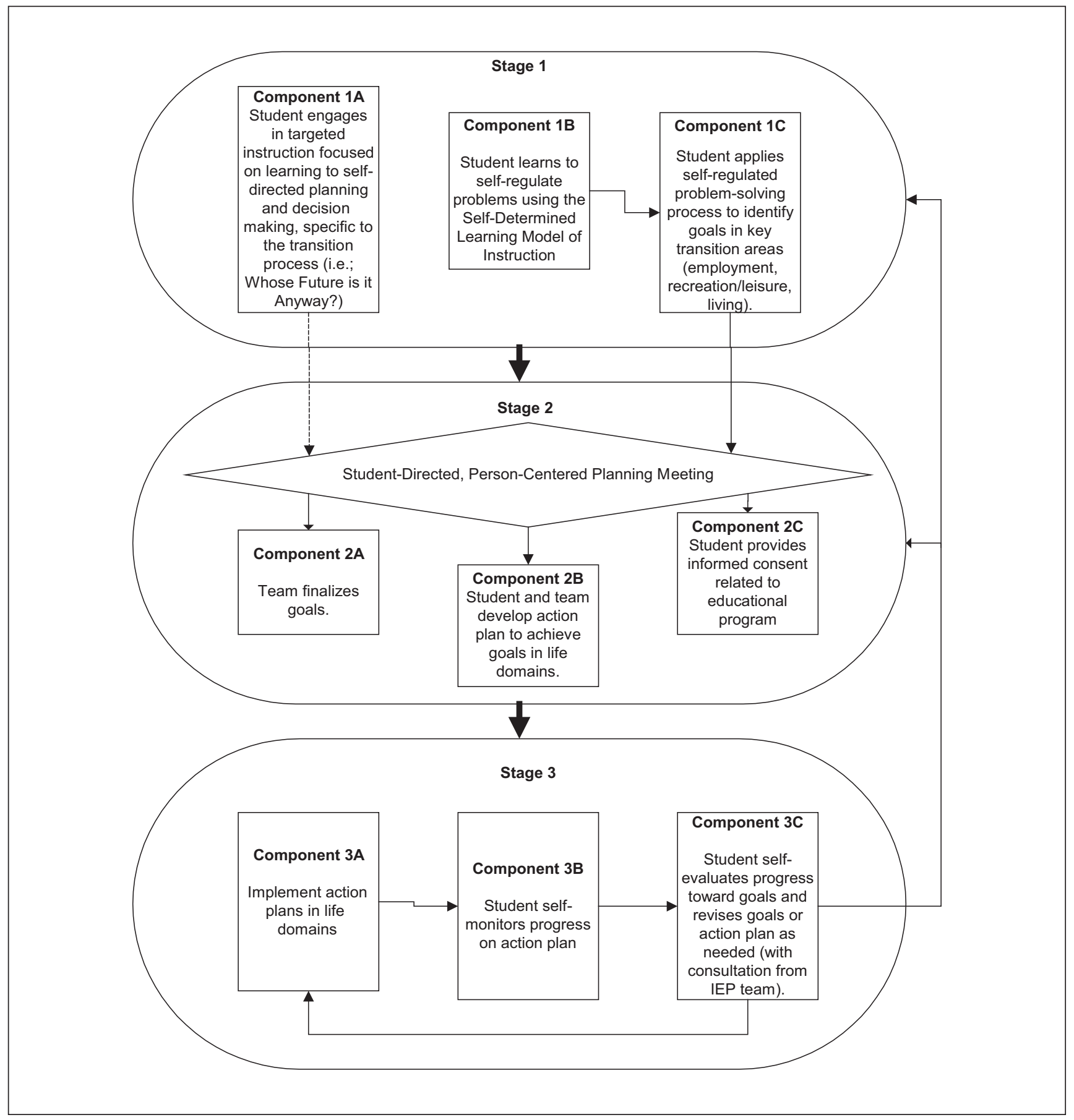

Figure I. Beyond High School model

Note: IEP = Individualized Education Program.

achievable. This is also an opportune time to consider how each stakeholder can support and contribute to the student's efforts to attain those goals.

During the final stage (Stage 3) of the BHS model, the student, with supports identified from the second stage, implements the plan, monitors his or her progress in achieving the goal, and evaluates success of the plan, making revisions to the goal or the plan as warranted. This is accomplished using the strategies and questions comprising the third phase of the SDLMI.

Wehmeyer and colleagues (2006) conducted a pilot evaluation of the impact of the BHS model with students receiving 18-21 services, determining that students involved in the process were able to achieve self-set goals, as 
Table I. Means and Standard Deviations for The Arc's SelfDetermination Scale by Disability and IQ Level

\begin{tabular}{|c|c|c|c|c|}
\hline \multirow[b]{2}{*}{ Group } & \multicolumn{2}{|c|}{ Pretest } & \multicolumn{2}{|c|}{ Posttest } \\
\hline & $M$ & $S D$ & $M$ & $S D$ \\
\hline \multicolumn{5}{|c|}{ Mild intellectual disability } \\
\hline Females & 101.4 & 24.3 & 105.7 & 13.5 \\
\hline Males & 93.2 & 19.9 & 100.1 & 19.8 \\
\hline \multicolumn{5}{|c|}{ Moderate intellectual disability } \\
\hline Females & 81.4 & 26.0 & 85.3 & 21.4 \\
\hline Males & 81.4 & 20.9 & 91.0 & 20.7 \\
\hline
\end{tabular}

measured by the Goal Attainment Scaling process, and showed gains in autonomous functioning.

\section{Instrumentation}

Participating teachers provided demographic information on participating students, using a standard demographic form created for the study. Teachers, along with project personnel as needed, also administered our primary outcome measure to participating students in individual or group sessions, depending on the needs of the students and the school district, after being trained in the appropriate administration protocol.

The Arc's Self-Determination Scale (SDS). The SDS (Wehmeyer \& Kelchner, 1995) is a 72-item self-report measure based on the functional theory of self-determination. A total of 148 points are available on the scale, with higher scores indicating higher levels of self-determination. An overall self-determination score and subscale scores for each of the four essential characteristics of self-determined behavior - autonomy, self-regulation, psychological empowerment, and self-realization (Wehmeyer, Kelchner, \& Richards, 1996) — can be calculated. The SDS was developed and normed with 500 adolescents with cognitive disabilities (Wehmeyer, 1996). Subsequent research (Shogren et al., 2008; Shogren, Lopez, Wehmeyer, Little, \& Pressgrove, 2006) verified the proposed theoretical structure of the SDS (i.e., four related but distinct subscales [autonomy, selfregulation, psychological empowerment, and self-realization] that contribute to a higher-order self-determination construct). In this study, Cronbach's alpha for the SDS at Time 1 was .90 and at Time 2 was .91 .

\section{Analytic Plan}

We implemented a longitudinal design to describe and evaluate changes in student self-determination scores as a function of participation in the BHS intervention. Specifically, we compared preintervention and postintervention selfdetermination scores of students with disabilities who partici-

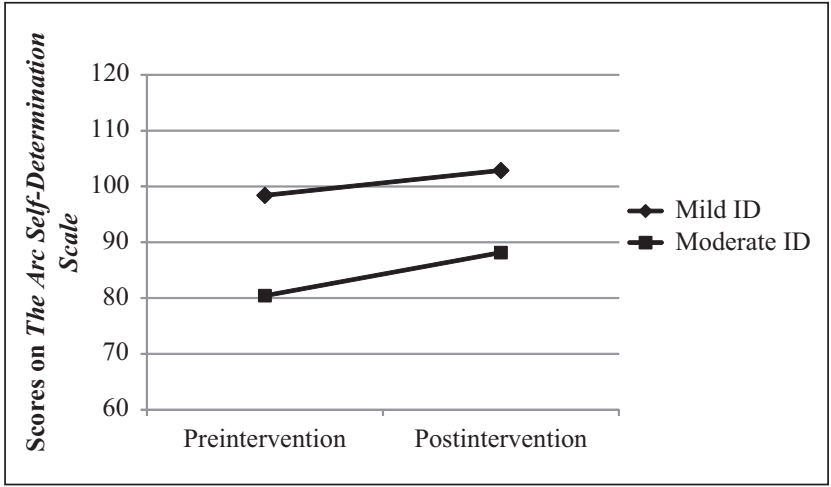

Figure 2. Estimated marginal means for The Arc SelfDetermination Scale by disability group

pated in the BHS intervention. We used mixed-factor analyses of variance (ANOVAs) with time (pre- and postscores on the SDS) as the within-participants factor and intellectual impairment level (e.g., mild, moderate) and gender as between-participants factors (Arkkelin, n.d.).

\section{Results}

Means and standard deviations for the SDS are presented in Table 1. A mixed-factor ANOVA with time as the withinparticipants factor and student intellectual impairment level and gender as the between-participants factors was conducted. For The Arc Self-Determination Scale, there was a significant overall effect of time (Wilks's Lambda $=0.93$; $F(1,69)=5.05, p=.03$; partial $\left.\eta^{2}=.10\right)$ with students showing a significant increase in their self-determination scores from baseline to postintervention. A significant main effect was found for intellectual impairment level, $F(1,69)=14.83, p<.001$; partial $\eta^{2}=.18$. There was no significant main effects of gender, $F(1,69)=0.46, p>.05$, nor any significant interactions. Thus, there was a significant change in student self-determination scores from baseline to postintervention, and this significant change was offset by initial differences based on intellectual impairment level, with students with mild intellectual impairments demonstrating higher initial scores. However, both groups of students showed the same pattern of change over time as shown in Figure 2. Thus, the BHS model shows promise for additional study, to determine if the differences over time with the two groups observed here are evident in additional studies, and the use of a complex control group design reflects promise for evidence of use of BHS in 18- to 21-year-old services.

\section{Discussion}

The results of this study provide preliminary support to the assertion that implementation of the BHS model contrib- 
utes to enhanced self-determination. Prior to discussing these findings, it is important to note a number of limitations that affect the interpretation and generalizability of these findings. First, this study used a simple longitudinal design and, as such, cannot claim causal attribution between the intervention and self-determination-related outcomes because no control group was used. Furthermore, changes in scores may reflect, simply, age-related development. Previous research on components of the BHS model, described subsequently, suggest that changes are more than just age-related changes, but nevertheless, there is a need for a larger scale, controlled study to evaluate the impact of the intervention. Second, as we have described, there was, inevitably, some attrition within the study sample. Though such attrition occurred because of typical reasons (most frequently that the student moved or changed schools), we cannot dismiss the possibility that this attrition introduced bias into the sample and affected the generalizability of the study's findings. Third, we had to use proxy (e.g., teacher report) indicators of student level of intellectual impairment. Although all students received special education under the categorical area of intellectual disability, we do not have IQ scores to verify that but instead use teacher knowledge of the student ability based on day-to-day functioning and amount of support needed to promote positive student outcomes. An additional limitation is the lack of direct observation as fidelity of implementation datadocumenting use of the intervention and whether the BHS model was used in its entirety over the course of the study or adapted considerably over time.

These limitations taken into consideration, we would note that these results are consistent with findings from several recent studies providing causal evidence for gains in self-determination for students receiving instruction to promote self-determination. Wehmeyer, Palmer, Shogren, Williams-Diehm, and Soukup (in press) conducted a randomized-trial control group study of the effect of interventions to promote the self-determination of high school students with cognitive disabilities. Students in a treatment group $(n=235)$ received instruction using a variety of instructional methods to promote self-determination and student involvement in educational planning meetings over 3 years; students in the control group $(n=132)$ received no such intervention. Self-determination was measured using two instruments across three measurement intervals. Using latent growth curve analyses, Wehmeyer and colleagues determined that students with cognitive disabilities who participated in intervention to promote self-determination over a 3-year period showed significantly more positive patterns of growth in their self-determination scores than did students not exposed to interventions to promote selfdetermination during the same time period.

With particular relevance to the present study, two elements of the BHS model have been tested independently for their impact on self-determination. The Wehmeyer et al. (2011) study discussed previously provides causal evidence of the efficacy of the WFA process, which was implemented as part of Stage 1 activities in this study. Wehmeyer et al. conducted a randomized-trial, placebo control group design to study the impact of intervention with the WFA process on self-determination and transition knowledge and skills. Results indicated that instruction using the WFA process resulted in significant, positive differences in self-determination when compared with a placebo control group and that students who received instruction gained transition knowledge and skills.

Finally, a recent study has documented the causal impact of intervention with the SDLMI to promote self-determination. The SDLMI forms the backbone for active student selfregulation of goal setting, action planning, and goal attainment evaluation in the BHS model. Wehmeyer, Shogren, et al. (in press) conducted a group-randomized, modified equivalent control group design study of the efficacy of the SDLMI to promote self-determination. Data on selfdetermination using multiple measures were collected with 312 high school students with cognitive disabilities in a control and a treatment group. Data on self-determination using multiple measures were collected on 312 high school students with cognitive disabilities in a control and a treatment group to investigate the relationship between the SDLMI and selfdetermination using structural equation modeling. After determining strong measurement invariance for each latent construct, Wehmeyer and colleagues found significant differences in latent means across measurement occasions and differential effects attributable to the SDLMI. This was true across disability category, though there was variance across disability populations.

The present study, when considered along with evidence of the causal impact of BHS components (WFA, SDLMI) on self-determination, and data from the pilot study of the effects of the WFA (Wehmeyer et al., 2006) on goal attainment, discussed previously, provide, we believe, a compelling, though clearly not causative, argument that implementing the WFA improves the self-determination of students with intellectual and cognitive disabilities. We would also add to the case for the model's potential impact findings from Williams-Diehm, Wehmeyer, Palmer, Soukup, and Garner (2008) that student involvement in transition planning, such as that targeted through implementation of the WFA model, has a reciprocal impact on student self-determination. Williams-Diehm and colleagues found that students who were more involved in transition planning were more selfdetermined and that, reciprocally, students who were more self-determined were more likely to be involved in their transition planning. The Wehmeyer, Palmer, et al. (in press) study also documented that students who received interventions to promote student involvement in educational planning were more self-determined, as a result of such 
instruction, than were their peers who were not similarly engaged in activities to promote student involvement.

\section{Implications for Research and the Improvement of Practice}

This study highlights the ability of students with intellectual disabilities to benefit from intervention involving instruction in self-determination that focuses on individual goals and benefits according to student strengths and needs. Students with intellectual disabilities learned skills using the BHS model, but the focus of this intervention is also on self-selected goals and objectives related to postschool outcomes. The benefits of direct instruction in selfdetermination for individuals with intellectual disabilities, including choice and decision making, goal setting, problem solving, self-monitoring, and self-regulation, are becoming more and more evident. Students with intellectual disabilities may not always be served in the most innovative settings (Gaumer et al., 2004), but families are generally satisfied with community access and social opportunities even through options could be better (Eisenman, Tanverdi, Perrington, \& Geiman, 2009).

It is clear that the expectations for students with intellectual disabilities from 18 to 21 are changing, as are the nature of the services being provided to these students. There is an increased opportunity for greater inclusion of students with intellectual disabilities in age-appropriate postsecondary settings. Whether such services are provided by the school district itself or by the postsecondary institution, there is a need to develop and evaluate models of intervention that move beyond just place-based discussion and begin to provide teachers with strategies to provide such instruction. It is critical that such efforts enable, to the maximum extent possible, students to self-direct planning and self-regulate learning. This study, along with prior evaluations of the BHS model and its components, establishes the model as a promising practice to achieve the outcome that students are actively engaged with their transition planning, have the tools to self-regulate goal setting and attainment, and, potentially, achieve greater self-determination and more positive transition outcomes, including attending postsecondary training on the college campus.

To expand on the idea of higher expectations for students with intellectual disabilities, in the current National Transition Longitudinal Study-2, Newman, Wagner, Cameto, Knokey, and Shaver (2010) found that students with intellectual disabilities had significantly higher rates of enrollment in advanced education from 1990 to 2005 moving from $8 \%$ to $28 \%$ attendance over that time. Will (2010) suggested,

For many reasons postsecondary education is a most important key to shaping a new reality for people with disabilities, It has the exciting potential to create a future based not on low expectations, the can't and shouldn't, but on the high expectations of productivity and person and economic freedom. (p. xii)

A recent initiative by the U.S. Department of Education's Office of Postsecondary Education has provided a catalyst to a decade-long movement to provide educational opportunities to students with intellectual and related disabilities in 2- or 4-year college or university settings (Grigal et al., 2006; Hart, Grigal, Sax, Martinez, \& Will, 2006; Hart, Grigal, \& Weir, 2010; Hart, Zimbrich, \& Ghiloni, 2001; Neubert, Moon, Grigal, \& Redd, 2001; Papay, \& Bambara, 2011). The 2008 reauthorization of the Higher Education Opportunity Act (2008) contained provisions specific to postsecondary education for students with intellectual and related disabilities (Lee, 2009; Lee \& Will, 2010), including identifying students with intellectual disabilities as eligible for financial aid available through the Act and authorizing a model demonstration program. A total of 28 such model demonstration projects were funded under the Office of Postsecondary Education (OPE) Transition and Postsecondary Programs for Students With Intellectual Disabilities competition in Fiscal Year 2010, and the Think College! (Grigal \& Hart, 2010; http://www.thinkcollege. net/databases/programs-database/search?state $=0$ ) database of postsecondary education programs for students with intellectual and other disabilities identifies 157 such programs, including those funded through the Higher Education Act model demonstration projects. Thus, individuals with intellectual disabilities have further opportunities for postsecondary training that surpass the usual ones. This is a key idea that Wehmeyer (1999) highlighted in his functional model of self-determination-Increasing the many options for individuals with disabilities to experience learning and practice skills extends the expectations and opportunities to increase levels of self-determination over time.

\section{Conclusion}

BHS effectively combines several evidence-based practices to support students with intellectual disabilities receiving special education services during the high school years. Cobb, Lehmann, Newman-Gonchar, and Alwell (2009) concurred that "positive outcomes [regarding self-determination] seem best achieved or maximized by instructional or curriculum interventions that contain multiple components," (p. 113). Self-determination is a multifaceted construct that supports academic and transition-related outcomes for students with intellectual disabilities. Providing direct instruction, making sure multiple opportunities to experience and practice emerging self-determination abilities such as problem solving and goal setting are available, and having high expectations for students with intellectual disabilities can 
continue to provide positive outcomes for students. Students with intellectual disabilities, their families, and services providers need to explore new opportunities such as postsecondary education within a college setting to maximize opportunity for enhancing self-determination and skill development. One way to support enhanced self-determination for students with intellectual disabilities in high school is the use of the BHS model. This model shows promise to help build individual capacity through direct and guided instruction in setting and achieving goals and by enhancing the opportunities that must be available to students with intellectual disabilities on exit from high school.

\section{Authors' Note}

The contents of this report do not necessarily represent the policy of the Department of Education, and endorsement by the Federal Government should not be assumed.

\section{Declaration of Conflicting Interests}

The author(s) declared no potential conflicts of interest with respect to the research, authorship, and/or publication of this article.

\section{Funding}

The author(s) disclosed receipt of the following financial support for the research, authorship, and/or publication of this article: Funding for this research was provided by Grant PR Award\# H133A031727 from the U.S. Department of Education, National Institute on Disability and Rehabilitation; and Grant PR Award\# R324B070159 from the U.S. Department of Education, Institute of Education Sciences, National Center for Special Education Research.

\section{References}

Arkkelin, D. (n.d.). Using SPSS to understand research and data analysis. Retrieved from http://wwwstage.valpo.edu/other/ dabook/home.htm

Burgstahler, S. (2001). A collaborative model to promote career success for students with disabilities. Journal of Vocational Rehabilitation, 16, 209-215.

Cobb, B., Lehmann, J., Newman-Gonchar, R., \& Alwell, M. (2009). Self-determination for students with disabilities: A narrative metasynthesis. Career Development for Exceptional Individuals, 32, 108-114.

Eisenman, L.T. (2001). Conceptualizing the contribution of career-oriented schooling to self-determination. Career Development for Exceptional Individuals, 24, 3-17.

Eisenman, L. T., Tanverdi, A., Perrington, C., \& Geiman, A. (2009). Secondary and postsecondary community activities of youth with significant intellectual disabilities. Education and Training in Developmental Disabilities, 44, 168-176.

Field, S., Sarver, M. D., \& Shaw, S. F. (2003). Self-determination: A key to success in postsecondary education for students with learning disabilities. Remedial and Special Education, 24, 339-349.
Gaumer, A. S., Morningstar, M. E., \& Clark, G. M. (2004). Status of community-based transition programs: A national database. Career Development for Exceptional Individuals, 27, 131-149.

Grigal, M., Dwyre, A., \& Davis, H. (2006). Transition services for students aged 18-21 with intellectual disabilities in college and community settings: Models and implications of success. National Center on Secondary Education and Transition Information Brief, 5, 1-5.

Grigal, M., \& Hart, D. (2010). Think College: Postsecondary education options for students with intellectual disabilities. Baltimore, MD: Paul H. Brookes.

Hart, D., Grigal, M., Sax, C., Martinez, D., \& Will, M. (2006). Postsecondary education options for students with intellectual disabilities (Research to Practice Issue No. 45). Boston, MA: Institute for Community Inclusion.

Hart, D., Grigal, M., \& Weir, C. (2010). Expanding the paradigm: Postsecondary education options for individuals with autism spectrum disorder and intellectual disabilities. Focus on Autism and Other Developmental Disabilities, 25, 134-150.

Hart, D., Zimbrich, K., \& Ghiloni, C. (2001). Interagency partnerships and funding: Individual supports for youth with significant disabilities as they move into postsecondary education and employment options. Journal of Vocational Rehabilitation, 16, 145-154.

Higher Education Opportunity Act. (2008). Pub. L. No. 110-315. 122 STAT. 3078(2008).

Individuals With Disabilities Education Act. (2004). 20 U.S.C. 1416(a)(3)(B).

Lee, S. S. (2009). Overview of the federal Higher Education Opportunities Act reauthorization (Institute on Community Inclusion Think College!). Policy Brief, 1, 1-2.

Lee, S. S., \& Will, M. (2010). The role of legislation, advocacy, and systems change in promoting post-secondary opportunities for students with intellectual disabilities. In M. Grigal \& D. Hart (Eds.), Think College: Postsecondary education options for students with intellectual disabilities (pp. 29-48). Baltimore, MD: Paul H. Brookes.

Neubert, D. A., Moon, M. S., Grigal, M., \& Redd, V. (2001). Postsecondary educational practices for individuals with mental retardation and other significant disabilities: A review of the literature. Journal of Vocational Rehabilitation, 16, 155-168.

Newman, L., Wagner, M., Cameto, R., Knokey, A.-M., \& Shaver, D. (2010). Comparisons across time of the outcomes of youth with disabilities up to 4 Years after high school. A report of findings from the National Longitudinal Transition Study (NLTS) and the National Longitudinal Transition Study-2 (NLTS2) (NCSER 2010-3008). Menlo Park, CA: SRI International.

No Child Left Behind Act (NCLB) (2001) http://www2.ed.gov/ policy/elsec/leg/esea02/index.html

Papay, C. K., \& Bambara, L. M. (2011). Postsecondary education for transition-age students with intellectual and other developmental disabilities: A national survey. Education and Training in Autism and Developmental Disabilities, 46, 78-93. 
Race to the Top. (2010). Available from http://racetotop.com/ Shogren, K. A., Lopez, S. J., Wehmeyer, M. L., Little, T. D., \& Pressgrove, C. L. (2006). The role of positive psychology constructs in predicting life satisfaction in adolescents with and without cognitive disabilities: An exploratory study. Journal of Positive Psychology, 1, 37-52.

Shogren, K. A., Palmer, S., Wehmeyer, M. L., Williams-Diehm, K., \& Little, T. (in press). Effect of intervention with the SelfDetermined Learning Model of Instruction on access and goal attainment. Remedial and Special Education. Advance online prepublication. doi:10.1177/07419352511410072

Shogren, K. A., Wehmeyer, M. L., Palmer, S. B., Soukup, J. H., Little, T., Garner, N., \& Lawrence, M. (2008). Understanding the construct of self-determination: Examining the relationship between The Arc's Self-Determination Scale and the American Institute for Research Self-Determination Scale. Assessment for Effective Instruction, 33, 94-107.

Stodden, R. A., Galloway, L. M., \& Stodden, N. J. (2003). Secondary school curricula issues: Impact on postsecondary students with disabilities. Exceptional Children, 70, 9-25.

Test, D. W., Mazzotti, V. L., Mustian, A. L., Fowler, C. H., Kottering, L., \& Kohler, P. (2009). Evidence-based secondary transition predictors for improving postschool outcomes for students with disabilities. Career Development for Exceptional Individuals, 32, 160-181.

Thoma, C. A., \& Getzel, E. E. (2005). "Self-determination is what it's all about": What post secondary students with disabilities tell us are important considerations for success. Education and Training in Developmental Disabilities, 40, 234-242.

Wehmeyer, M. L. (1996). Student self-report measure of selfdetermination for students with cognitive disabilities. Education and Training in Mental Retardation and Developmental Disabilities, 31, 282-293.

Wehmeyer, M. L. (1999). A functional model of self-determination: Describing development and implementing instruction. Focus on Autism and Other Developmental Disabilities, 14, 53-61.

Wehmeyer, M. L., Garner, N., Lawrence, M., Yeager, D., \& Davis, A. K. (2006). Infusing self-determination into 18-21 services for students with intellectual or developmental disabilities: A multi-stage, multiple component model. Education and Training in Developmental Disabilities, 41, 3-13.

Wehmeyer, M. L., \& Kelchner, K. (1995). The Arc's Self-Determination Scale. Arlington, TX: The Arc National Headquarters.

Wehmeyer, M. L., Kelchner, K., \& Richards, S. (1996). Essential characteristics of self-determined behavior of individuals with mental retardation. American Journal on Mental Retardation, $100,632-642$.
Wehmeyer, M. L., \& Lawrence, M. (1995). Whose Future Is It Anyway? Promoting student involvement in transition planning with a student-directed process. Career Development for Exceptional Individuals, 18, 69-83.

Wehmeyer, M. L., \& Schwartz, M. (1997). Self-determination and positive adult outcomes: A follow-up study of youth with mental retardation or learning disabilities. Exceptional Children, 63, 245-255.

Wehmeyer, M. L. (2003). A functional theory of self-determination: Definition and categorization. In M. L. Wehmeyer, B. H. Abery, D. E. Mithaug, \& R. J. Stancliffe (Eds). Theory in SelfDetermination: Foundations for Educational Practice (pp. 174-181). Springfield, IL: Thomas.

Wehmeyer, M. L., Lawrence, M., Kelchner, K., Palmer, S., Garner, N., \& Soukup, J. (2004). Whose Future Is It Anyway? A student-directed transition planning process (2nd ed.). Lawrence, KS: Beach Center on Disability.

Wehmeyer, M. L., \& Palmer, S. B. (2003). Adult outcomes for students with cognitive disabilities three years after high school: The impact of self-determination. Education and Training in Developmental Disabilities, 38, 131-144.

Wehmeyer, M. L., Palmer, S. B., Agran, M., Mithaug, D., \& Martin, J. (2000). Promoting causal agency: The SelfDetermined Learning Model of Instruction. Exceptional Children, 66, 439-453.

Wehmeyer, M. L., Palmer, S. B., Lee, Y., Williams-Diehm, K., \& Shogren, K. A. (2011). A randomized-trial evaluation of the effect of Whose Future Is It Anyway? on self-determination. Career Development for Exceptional Individuals, 34, 45-56.

Wehmeyer, M. L., Palmer, S. B., Shogren, K., Williams-Diehm, K., \& Soukup, J. (in press). Establishing a causal relationship between interventions to promote self-determination and enhanced student self-determination. Journal of Special Education. Prepublished December 10, 2010, doi: 10.1177/0022466910392377.

Wehmeyer, M. L., Shogren, K., Palmer, S. B., Williams-Diehm, K., Little, T., \& Boulton, A. (2012). Impact of the Self-Determined Learning Model of Instruction on student self-determination: A randomized-trial placebo control group study. Exceptional Children, 78, 135-153.

Will, M. (2010). Foreword. In M. Grigal \& D. Hart (Eds.), Think College: Postsecondary education options for students with intellectual disabilities (p. xii). Baltimore, MD: Paul H. Brookes.

Williams-Diehm, K., Wehmeyer, M. L., Palmer, S., Soukup, J. H., \& Garner, N. (2008). Self-determination and student involvement in transition planning: A multivariate analysis. Journal on Developmental Disabilities, 14, 25-36. 